\title{
MEROMORPHIC MATRIX TRIVIALIZATIONS OF FACTORS OF AUTOMORPHY OVER A RIEMANN SURFACE
}

\author{
Joseph A. Ball, Kevin F. Clancey and Victor Vinnikov
}

\begin{abstract}
It is a consequence of the Jacobi Inversion Theorem that a line bundle over a Riemann surface $M$ of genus $g$ has a meromorphic section having at most $g$ poles, or equivalently, the divisor class of a divisor over $M$ contains a divisor having at most $g$ poles (counting multiplicities). We explore various analogues of these ideas for vector bundles and associated matrix divisors over $M$. The most explicit results are for the genus 1 case. We also review and improve earlier results concerning the construction of automorphic or relatively automorphic meromorphic matrix functions having a prescribed null/pole structure.
\end{abstract}

Mathematics subject classification (2010): 14D20, 30F10, 30F35, 47A48.

Keywords and phrases: holomorphic vector bundle, factor of automorphy, zero/pole interpolation problems, Abel-Jacobi map, theta functions, transfer-function realization.

\section{REFERENCES}

[1] Daniel Alpay and Victor Vinnikov, Finite dimensional de Branges Spaces on Riemann surfaces, J. Funct. Anal. 189 (2002), 283-324.

[2] Michael Atiyah, Vector bundles over an elliptic curve, Proc. London Math. Soc. (3) 7 (1957), 414-452.

[3] JosePh A. BALL, Operator extremal problems, expectation operators and applications to operators on multiply connected domains, J. Operator Theory 1 (1979), 153-175.

[4] Joseph A. Ball and Kevin F. Clancey, Interpolation with meromorphic matrix functions, Proc. Amer. Math. Soc. 121 (1994) no. 2, 491-496.

[5] Joseph A. Ball, Kevin F. Clancey and Victor Vinnikov, Concrete interpolation of meromorphic matrix functions on Riemann surfaces, in: Interpolation Theory, Systems Theory and Related Topics (Tel Aviv/Rehovot, 1999), Oper. Theory Adv. Appl. 134, pp. 137-156, Birkhäuser, Basel, 2002.

[6] Joseph A. Ball, IsRael Gohberg And Leiba Rodman, Interpolation of Rational Matrix Functions, Oper. Theory Adv. Appl. 45, Birkhäuser, Basel, 1990.

[7] Joseph A. BALl AND ANDRÉ C. M. RAN, Local inverse spectral problems for rational matrix functions, Integral Equations and Operator Theory 10 (1987) no. 3, 349-415.

[8] Joseph A. BALl AND ANDRÉ C. M. RAN, Global inverse spectral problems for rational matrix functions, Linear Algebra Appl. 86 (1987), 237-282.

[9] JosePh A. BALl AND VICTOR VINNIKOV, Zero-pole interpolation for meromorphic matrix functions on an algebraic curve and transfer functions of $2 D$ systems, Acta Applicandae Mathematicae $\mathbf{4 5}$ (1996), 239-316.

[10] Joseph A. BALl AND Victor Vinnikov, Zero-pole interpolation for matrix meromorphic functions on a compact Riemann surface and a matrix Fay trisecant identity, Amer. J. Math 121 no. 4 (1999), 841-888.

[11] Clifford J. Earle and Albert Marden, Poincaré series with applications to $H^{p}$-spaces on bordered Riemann surfaces, Illinois J. Math. 13 (1969), 274-278.

[12] Clifford J. Earle and Albert Marden, Projections to automorphic functions, Proc. Amer. Math. Soc. 19 (1968), 274-278. 
[13] Hershel M. Farkas and Irwin Kra, Riemann Surfaces, Graduate Texts in Mathematics 71 (Second Edition), Springer-Verlag, New York, 1992.

[14] John D. FAY, Theta Functions on Riemann Surfaces, Lecture Notes in Mathematics 352, Springer, 1973.

[15] Frank Forelli, Bounded holomorphic functions and projections, Illinois J. Math. 10 (1966), 367380.

[16] OtTo Forster, Lectures on Riemann Surfaces, Graduate Texts in Mathematics 81, Springer-Verlag, Berlin, 1981.

[17] Hans Grauert, Analytische Faserungen über holomorph-vollständigen Räumen, Math. Ann. 135 (1958), 263-273.

[18] Robert C. Gunning, Lectures on Vector Bundles over Riemann Surfaces, University of Tokyo Press, Tokyo, 1967.

[19] Robert C. Gunning, Riemann Surfaces and Generalized Theta Functions, Ergebnisse der Mathematik und ihrer Grenzgebiete, Band 91, Springer-Verlag, Berlin, 1976.

[20] V. E. KATSNELSON, Right and left joint system representation of a rational matrix function in general position (system representation theory for dummies), in: Operator Theory, System Theory and Related Topics (Beer-Sheva/Rehovot, 1997), Oper. Theory Adv. Appl., 123, pp. 337-400, Birkhäuser, Basel, 2001.

[21] Rick Miranda, Algebraic Curves and Riemann Surfaces, Graduate Studies in Mathematics 5, American Mathematical Society, Providence, 1995.

[22] David Mumford (with the collaboration of C. Musili, M. Nori, E. Previato, M. Stillman And H. Umenmura), Tata Lectures on Theta I, Progress in Mathematics 28, Birkhäuser-Boston, 1983; third printing 1994.

[23] David Mumford (with the collaboration of C. Musili, M. Nori, E. Previato, M. Stillman and H. Umenmura), Tata Lectures on Theta II, Progress in Mathematics 43, Birkhäuser-Boston, 1984; third printing 1993.

[24] Samuel Schechter, On the inversion of certain matrices, Mathematical Tables and Other Aids to Computation 13 (66) (1959), 73-77.

[25] Elias M. Stein and Rami Shakarchi, Complex Analysis, Princeton Lectures in Analysis II, Princeton University Press, Princeton and Oxford, 2003.

[26] André WeIL, Généralisation des fonctions abéliennes, J. Math. Pures Appl. (9) 17 (1938), 47-87. 